\title{
Energy Analysis of a Counter-Flow Plate Heat Exchanger Working in Stationary Mode and Using Geothermal Energy for Drying
}

Jean Pierre Tine, Biram Dieng, Mouhamadou Lamine Cisse and Marie Pascaline Sarr

Renewable Energy Research Team, Materials and Laser, Department of Physic, UFR SATIC, University Alioune DIOP of Bambey

(UADB), Bambey 21400, BP30, Senegal

\begin{abstract}
This paper presents an energy analysis of a counter-flow plate heat exchanger operating in stationary mode. The exchanger comprises a rectangular plate of which we vary the heat transfer surface (by fixing its width and varying its length) and analyze the evolution of some parameters as a function of this heat transfer surface. The parameters to be analyzed are the NTU (number of transfer units), the effectiveness, the temperatures of both primary and secondary fluids and the heat flux. The analysis carried out will help understand the behavior of the counter-flow plate heat exchanger operating in stationary mode. Then, the heat transfer surface of the exchanger is determined for the sizing of a counter-flow plate heat exchanger intended to produce hot air for drying. That plate heat exchanger uses water vapor heated by geothermal energy as a primary fluid and atmospheric air as a secondary fluid. The products to be dried are onions with a mass flow of water to be evacuated of $100 \mathrm{~kg} / \mathrm{h}$.
\end{abstract}

Key words: Exchanger, flux, temperature, geothermal, stationary mode.

\section{Nomenclature}

Symbol
$\dot{C}_{1}$
$\dot{C}_{2}$
$\dot{C}_{d r y_{-} a i r}$
$\dot{C}_{\text {wat_vapor }}$
$c_{p_{\text {air }}}$
$c_{p_{\text {wat_vapor }}}$
E
$h$
$h e$
$H r$
$K$
$\dot{m}$ air
$\dot{m} e$
$N T U$
$r$
$R e$
$\mathrm{~S}$

Corresponding author: Biram Dieng, Ph.D., professor, research field: solar and thermal energy.

Convective exchange coefficient $\mathrm{W} \cdot \mathrm{m}^{-2} \cdot \mathrm{K}^{-1}$ Specific enthalpy Relative humidity of air Overall heat transfer coefficient $\mathrm{kJ} / \mathrm{kg}_{\text {as }}$ $\%$ $\mathrm{W} \cdot \mathrm{m}^{-2} \cdot \mathrm{K}^{-1}$ $\mathrm{kg} / \mathrm{s}$ Mass flow rate of air $\mathrm{kg} / \mathrm{s}$ Number of transfer units Ratio of capacity flow rates Thermal resistance of fouling $\mathrm{m}^{2} \cdot \mathrm{K} \cdot \mathrm{W}^{-1}$ Heat transfer surface $\quad \mathrm{m}^{2}$

\begin{tabular}{|c|c|c|}
\hline$T$ & Temperature & \\
\hline$T_{e 1}$ & Inlet temperature of hot fluid & \\
\hline$T_{e 2}$ & Inlet temperature of cold fluid & \\
\hline$T_{s 1}$ & Outlet temperature of hot fluid & \\
\hline$T_{S 2}$ & $\begin{array}{l}\text { Outlet temperature of cold } \\
\text { fluid }\end{array}$ & \\
\hline$X$ & Absolute humidity & \\
\hline$\overline{\Delta T}$ & $\begin{array}{l}\text { Log-Mean Temperature } \\
\text { Difference }\end{array}$ & \\
\hline 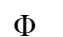 & Heat flux & \\
\hline
\end{tabular}

\section{Introduction}

Heat exchangers are practically used in all sectors of industry (chemistry, petrochemistry, food industry, energy production...), transport but also in the tertiary sector. There are several heat exchanger technologies including the plate heat exchanger. This one is of rather recent conception and is being more and more widespread [1].

The conception and the proper operation of a heat exchanger requires the understanding of the behavior of this heat exchanger. That can be done by analyzing some parameters such as the NTU (number of transfer 
units), the effectiveness, the temperatures of both hot and cold fluids and the heat flux. The analysis of these parameters will be carried out for a counter-flow plate heat exchanger operating in stationary mode. The exchanger comprises a rectangular plate of which we vary the heat transfer surface and analyze the evolution of the parameters as a function of this heat transfer surface. Then, the heat transfer surface needed by the exchanger to properly heat ambient air for the drying of products will be determined.

\section{Modeling of a Counter-Flow Heat Exchanger}

\subsection{Hypothesis}

The modeling of a counter-flow heat exchanger in stationary mode is based on assumptions that we define before doing the modeling.

- The exchanger operates in stationary mode $(\partial / \partial \mathrm{t}=0)$;

- The heat transfer is perpendicular to the exchange surface;

- The overall heat transfer coefficient $K$ is constant;

- The mass flow rates of both fluids are conservative;

- There is no heat loss and the heat flux is conservative;

- All heat released by the hot fluid is entirely absorbed by the cold fluid.

\subsection{LMTD (Log-Mean Temperature Difference)}

Considering the hypothesis listed above, the total heat flux can be written as follows [2]:

$$
\Phi=K P \int_{0}^{L} \Delta T(x) d x=\mathrm{KS} \overline{\Delta T}
$$

The LMTD can be expressed as a function of the temperatures at both ends of the heat exchanger by the following equation $[2,3]$ :

$$
\overline{\Delta T}=\frac{(\Delta T)_{i}-(\Delta T)_{o}}{\ln \frac{(\Delta T)_{i}}{(\Delta T)_{o}}}
$$

$(\Delta T)_{i}=T_{e 1}-T_{s 2}:$ Difference in temperature between the hot fluid (fluid 1) and the cold fluid (fluid 2) in counter-flow at the inlet;

$(\Delta T)_{o}=T_{s 1}-T_{e 2}:$ Difference in temperature between the hot fluid (fluid 1) and the cold fluid (fluid 2) in counter-flow at the outlet.

\subsection{Effectiveness and NTU}

\subsubsection{Effectiveness}

The effectiveness is defined as the ratio between the actual heat flux transferred into the exchanger of finite length and the maximum possible heat flux transferable in the exchanger of infinite length [3]:

$$
E=\frac{\Phi}{\Phi_{\max }}
$$

There are two expressions of the effectiveness [3] (expressed as a function of the temperatures at the ends of the exchanger) depending on whether the hot fluid or the cold fluid has the lowest heat capacity rate $\dot{C}$.

If the hot fluid has the lowest heat capacity rate, $\left(\dot{C}_{1}<\dot{C}_{2}\right)$ then:

$$
E=\frac{\left(T_{e 1}-T_{s 1}\right)}{\left(T_{e 1}-T_{e 2}\right)}
$$

If the cold fluid has the lowest heat capacity rate, $\left(\dot{C}_{1}>\dot{C}_{2}\right)$ then:

$$
E=\frac{\left(T_{s 2}-T_{e 2}\right)}{\left(T_{e 1}-T_{e 2}\right)}
$$

\subsubsection{NTU}

The NTU is a dimensionless quantity representative of the capability of the exchanger to transfer heat. The NTU is calculated considering the fluid that has the lowest heat capacity rate and is expressed by the following equation [4-6]:

$$
N U T \frac{K S}{\dot{C}_{\min }}
$$

2.3.3 Relationship between Effectiveness and NTU By introducing the ratio of capacity rates defined by:

$$
r=\frac{\dot{C}_{\min }}{\dot{C}_{\max }}
$$

The effectiveness can be expressed as a function of 
the NTU and vice versa. The equations are mentioned below:

$$
\begin{gathered}
N U T=\frac{1}{1-\mathrm{r}} \ln \left(\frac{1-r E}{1-\mathrm{E}}\right) \\
E=\frac{1-\exp [-\mathrm{NUT}(1-\mathrm{r})]}{1-\mathrm{r} \cdot \exp [-\mathrm{NUT}(1-\mathrm{r})]}
\end{gathered}
$$

\section{Energy Analysis according to the Heat Transfer Surface}

In this part, we vary the heat transfer surface of the heat exchanger (by fixing the width of the rectangular plate and varying the length) and analyze the evolution of the following parameters:

- The NTU
- The effectiveness

- The temperatures of both fluids

- The heat flux

Also, the parameters below are assumed to be known:

- The heat capacity rates of both fluids $\dot{C}_{1}$ and $\dot{C}_{2}$

- The temperatures at the inlet of the exchanger

- The heat transfer coefficient $\mathrm{K}$

\section{$3.1 N T U$}

By using the NTU expression in Eq. (5), and considering that the cold fluid (fluid 2) has the lowest capacity rate, we can determine the evolution of the NTU as a function of the heat transfer surface:

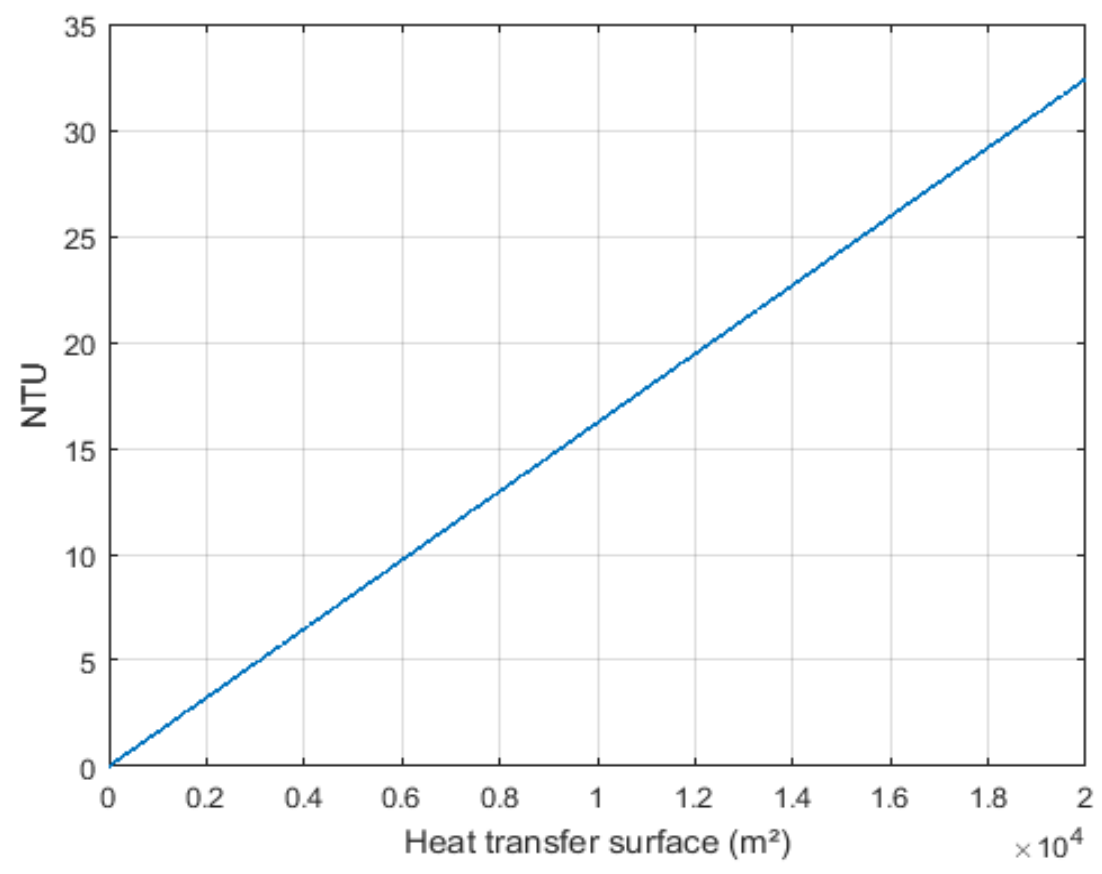

Fig. 1 NTU evolution. 
The NTU is an increasing linear function of the variable $S$ which is the heat transfer surface of the exchanger (Fig. 1).

\subsection{Effectiveness $E$}

Knowing the evolution of the NTU, we can deduce the evolution of the effectiveness by using Eq. (8) which expresses the effectiveness as a function of the NTU:

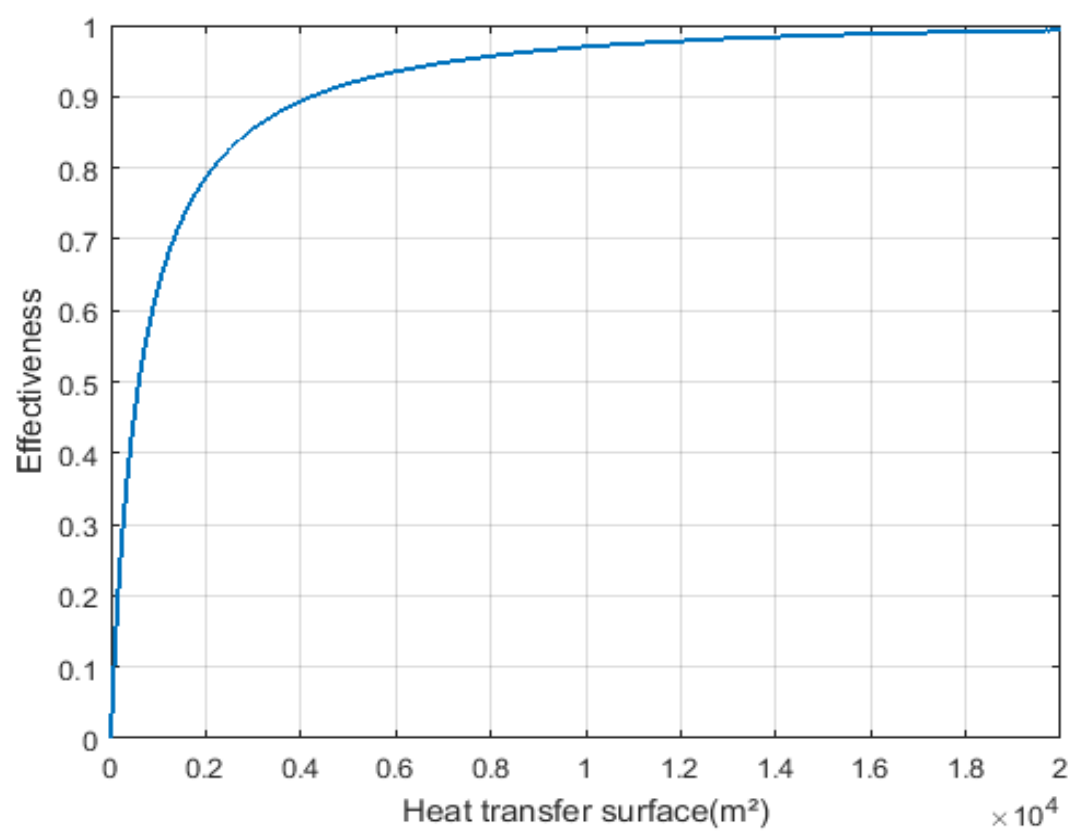

Fig. 2 Effectiveness evolution.

The effectiveness varies from 0 to 1 . It tends to 1 when the heat transfer surface of the exchanger tends to infinity (Fig. 2).

\subsection{Temperatures of Both Fluids}

Let us remember that we are in the case where the cold fluid (fluid 2) has the lowest capacity rate $\left(C_{1}>\right.$ $C_{2}$ ). The effectiveness can be written as follows:

$$
E(S)=\frac{T_{S 2}-T_{2}(S)}{T_{e 1}-T_{2}(S)}
$$

From this equation, we can deduce the expression of the temperature of the cold fluid as a function of the temperatures at the inlet and of the effectiveness:

$$
T_{2}(S)=\frac{E(S) * T_{e 1}-T_{s 2}}{E(S)-1}
$$

Knowing the evolution of the temperature of the cold fluid, we determine that of the temperature of the hot fluid by using the equation of conservation of the heat transferred:

$$
T_{1}(S)=T_{e 1}-r *\left(T_{s 2}-T_{2}(S)\right)
$$

Both evolutions are illustrated in Fig. 3 below. 


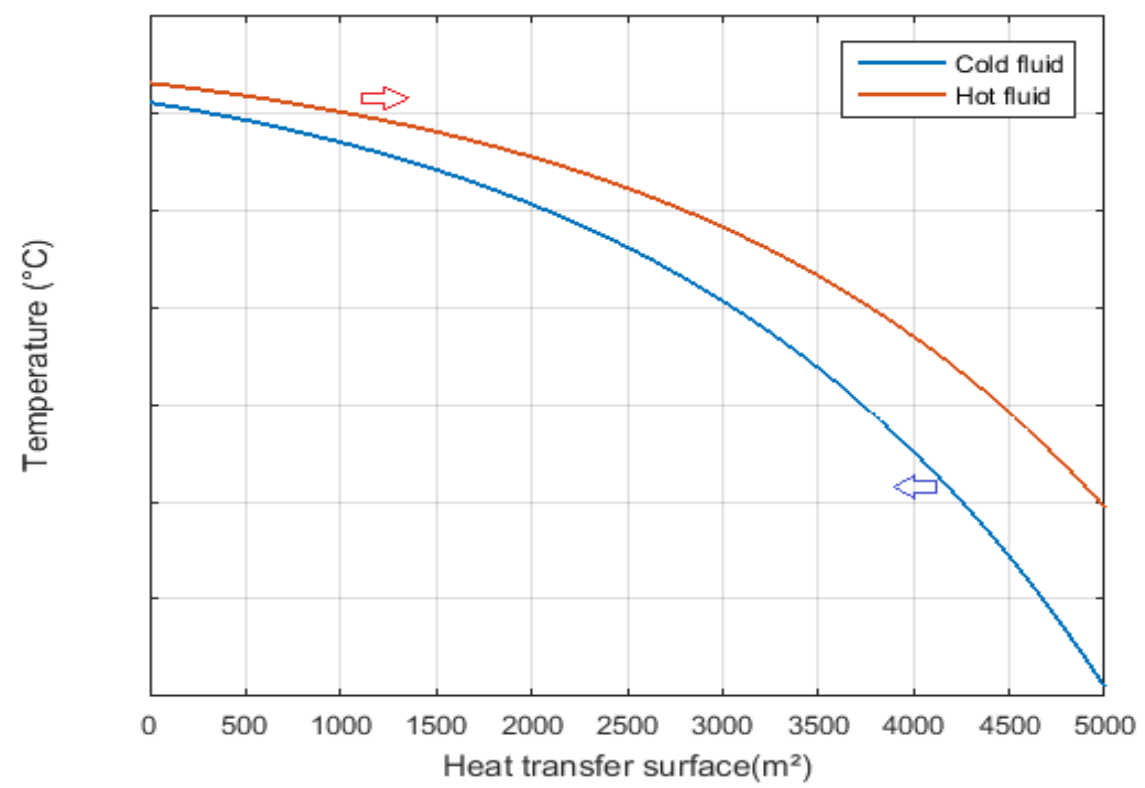

Fig. 3 Evolution of the hot and cold temperatures for $C_{1}>C_{2}$.

As the exchange surface increases, the temperature of the cold fluid increases and tends to the inlet temperature of the hot fluid. The temperature of the hot fluid decreases but will always be higher than the inlet temperature of the cold fluid (Fig. 3). That is true for a counter-flow heat exchanger especially when the cold fluid has the lowest heat capacity rate.
But when the hot fluid has the lowest heat capacity rate, its temperature decreases and tends to the inlet temperature of the cold fluid when the exchange surface increases. In the meanwhile, the temperature of the cold fluid increases but will always be lower than the inlet temperature of the hot fluid (Fig. 4).

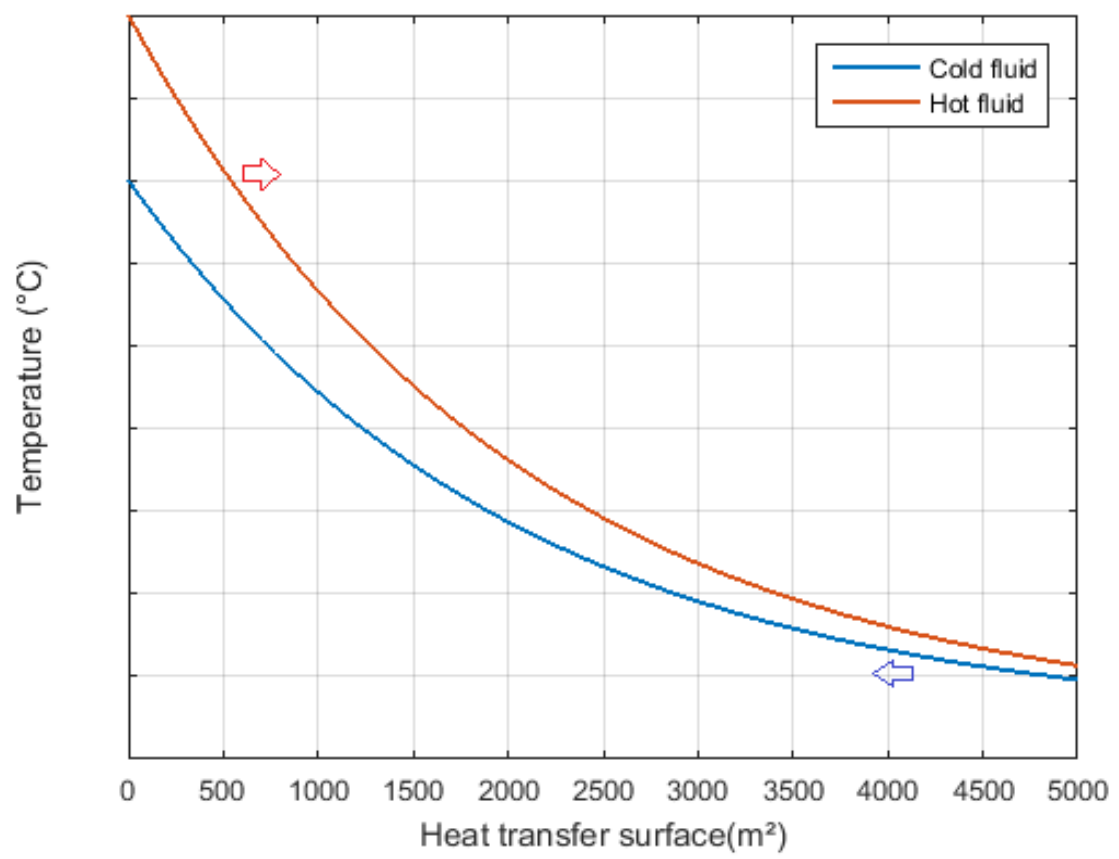

Fig. 4 Evolution of the hot and cold temperatures for $C_{1}<C_{2}$. 
Moreover, if the ratio of the heat capacity rates $r$ is very low (close to 0 ) the temperature of the fluid that has the lowest heat capacity rate tends quite rapidly to the inlet temperature of the other fluid when the exchange surface increases. And the temperature of the fluid that has the highest heat capacity rate remains almost constant (Figs. 5 and 6).

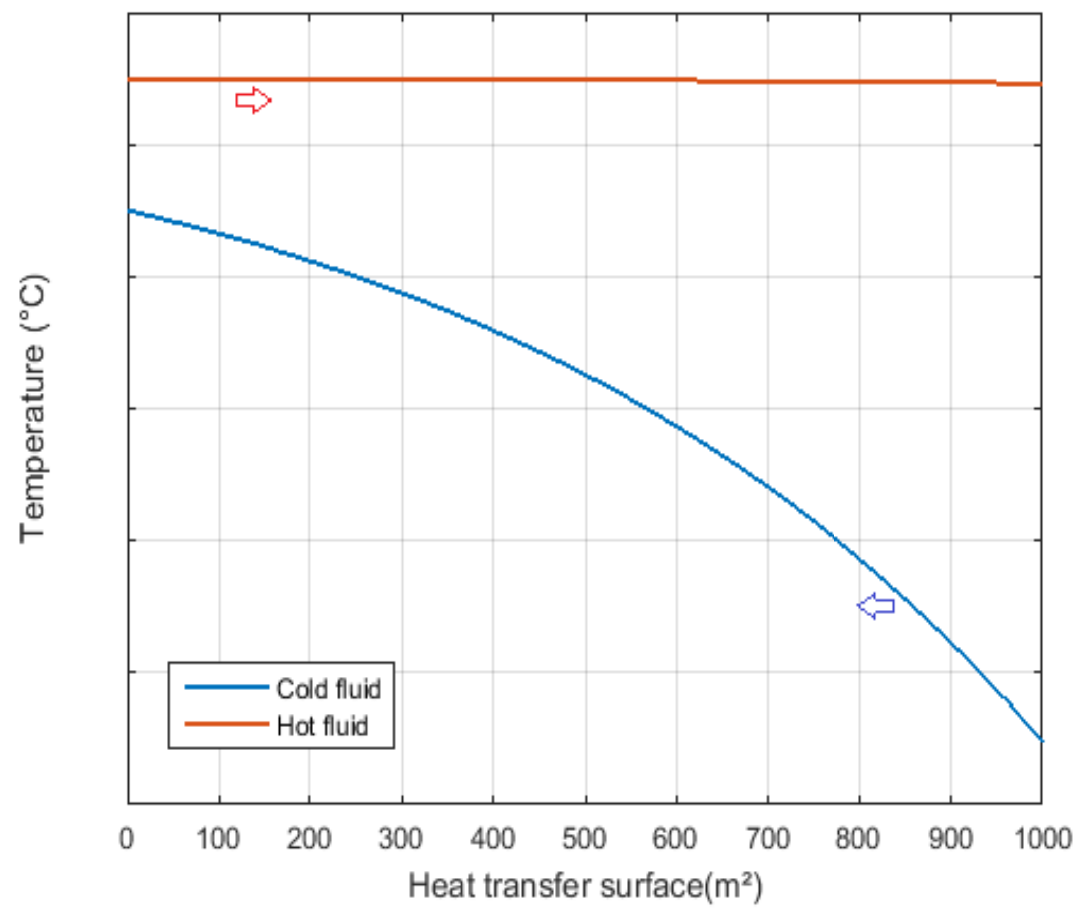

Fig. 5 Case where $C_{1} \gg C_{2}$.

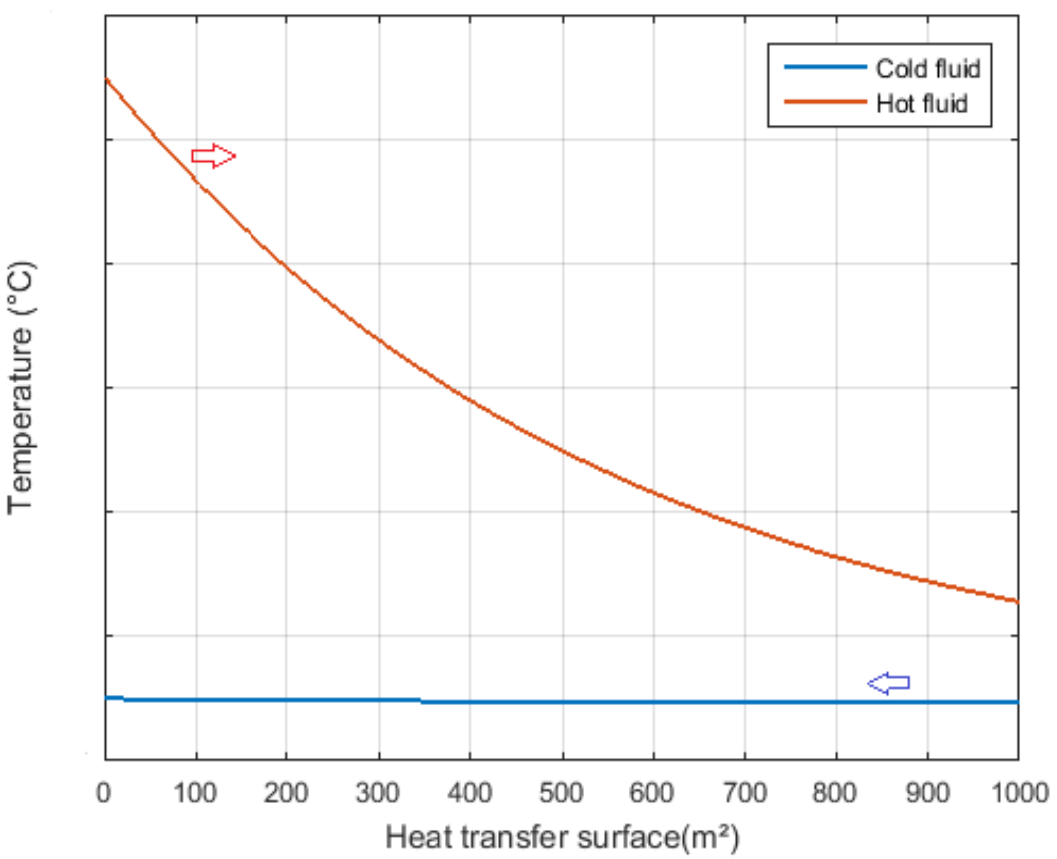

Fig. 6 Case where $C_{1} \ll C_{2}$. 


\subsection{Heat Flux}

To understand well the evolution of the heat flux as a function of the heat transfer surface, we also represent the evolution of the LMTD, since the heat flux, the heat transfer surface and the LMTD are linked by the equation below:

$$
\Phi=K S \overline{\Delta T}
$$

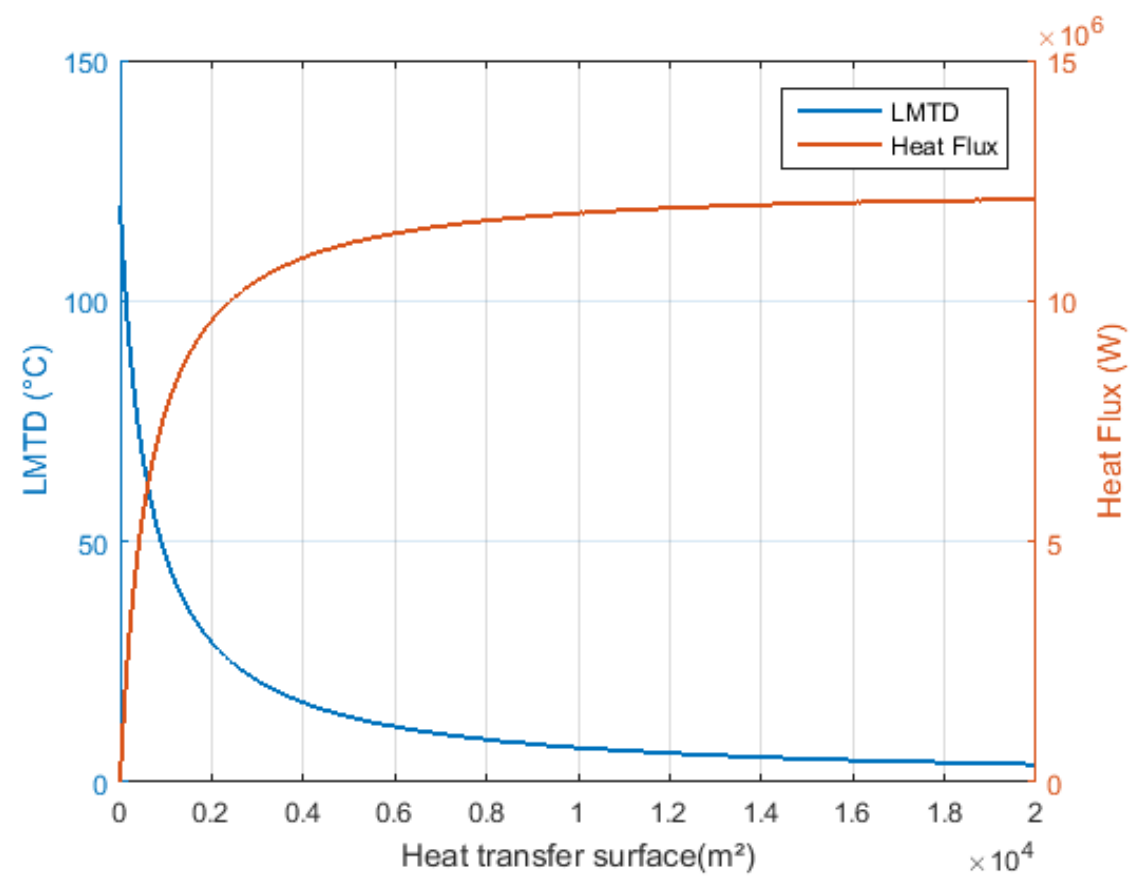

Fig. 7 LMTD and heat flux evolution

When the exchange surface tends to infinity, the LMTD tends to 0; this allows the heat flux to have a finite value and to prevent it from tending to infinity (Fig. 7).
We can also determine the influence of the ratio $r$ on the heat flux. To do so, we have represented the heat flux as a function of the exchange surface for different values of the ratio $r$. 


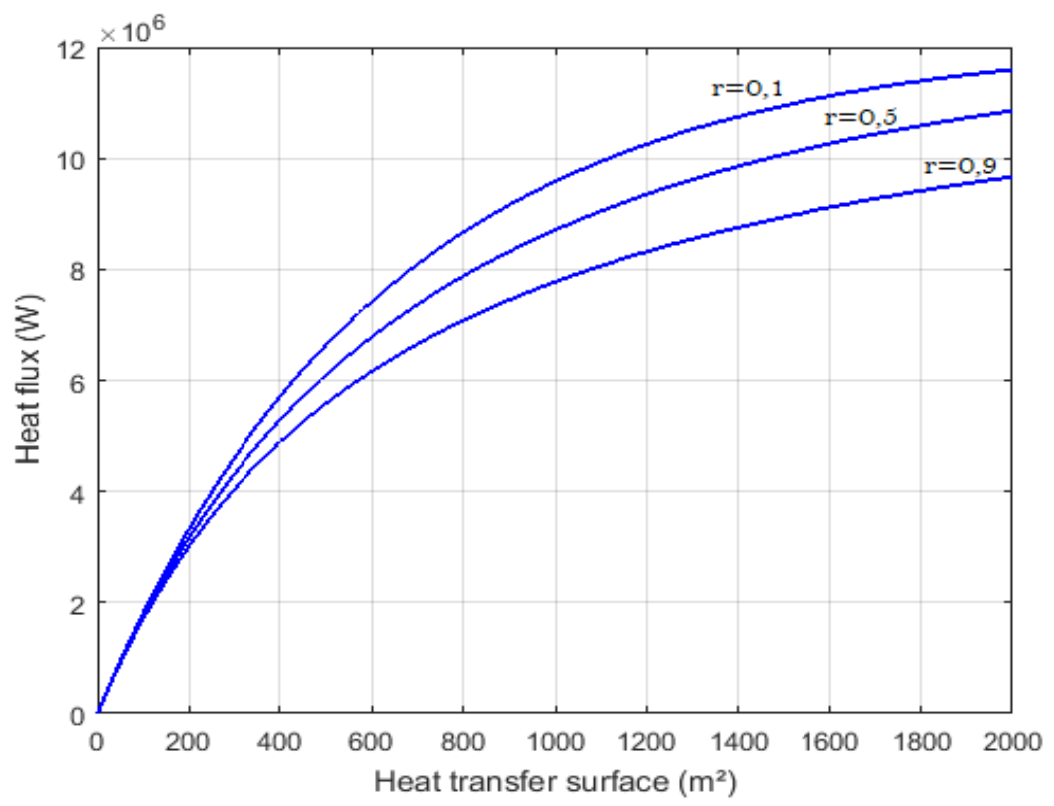

Fig. 8 Influence of the ratio $r$ on the heat flux.

We notice that the heat flux is more important when the ratio of the heat capacity rates is close to 0 (Fig 8).

\section{Application: Exchanger Heating Atmospheric Air for Drying}

In this part, we determine the heat transfer surface of a counter-flow plate heat exchanger using water vapor heated by geothermal energy as a primary fluid and atmospheric air as a secondary fluid. The exchanger is intended to heat ambient air for the drying of products (Fig. 9).
The products to be dried are onions that cannot withstand a temperature higher than $50{ }^{\circ} \mathrm{C}$. So the heated air must exit the heat exchanger at a temperature of $50{ }^{\circ} \mathrm{C}$. In addition, the air used at the inlet of the exchanger is the ambient air with a temperature of $30^{\circ} \mathrm{C}$ and a relative humidity of $20 \%$.

It is also assumed that after passing through the products, the relative humidity of the air will be $90 \%$ to avoid the condensation of the water vapor contained in the air.

And finally, the mass flow rate of water to extract from the onions will be $100 \mathrm{~kg} / \mathrm{h}$. 

Stationary Mode and Using Geothermal Energy for Drying

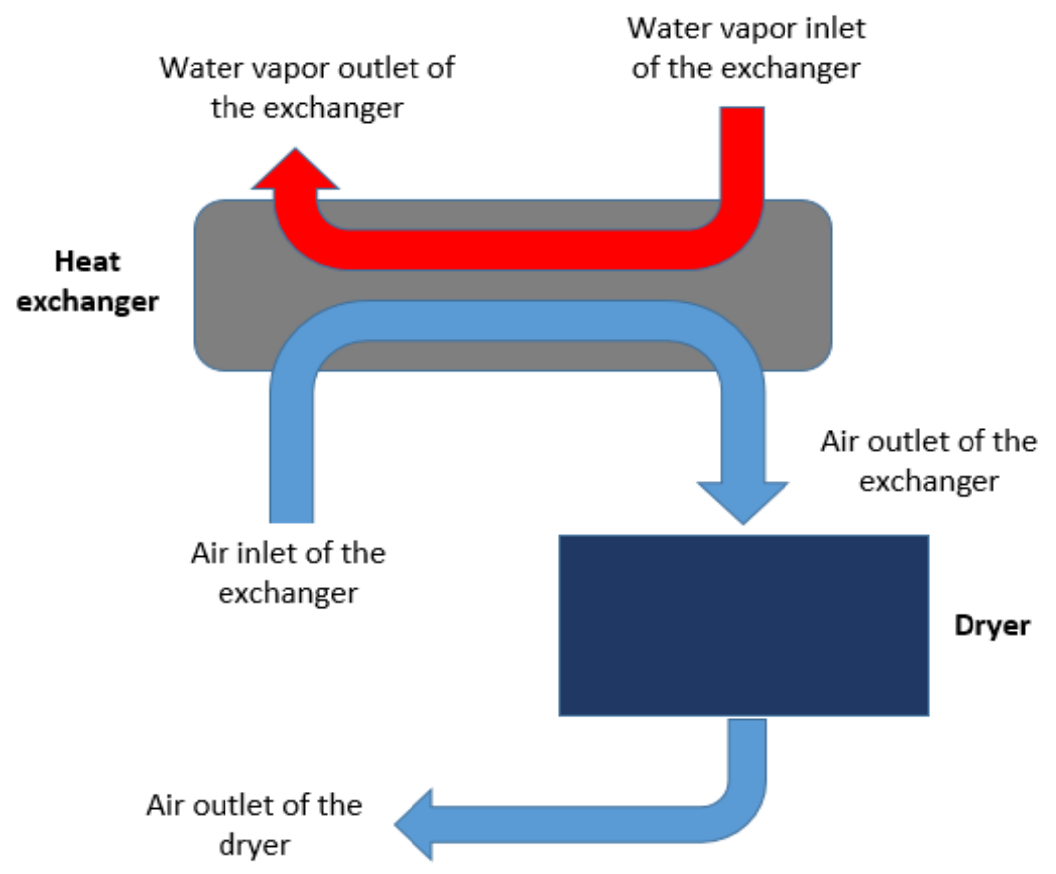

Fig. 9 Representation of the drying unit.

4.1 Determination of the Characteristics of the Cold Fluid (Air)

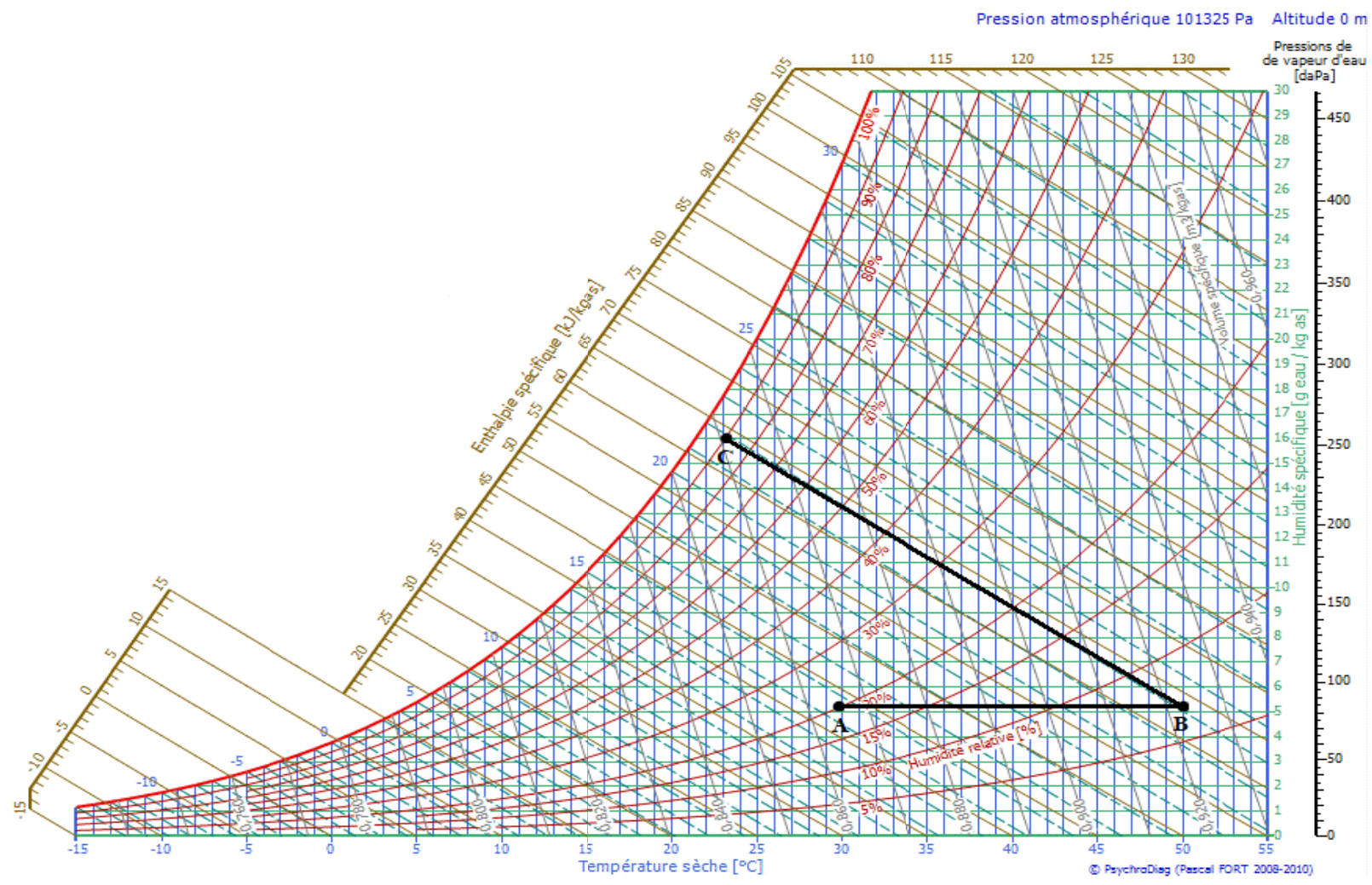

Fig. 10 Characteristics of the atmospheric air. 
4.1.1 Air at the Inlet of the Exchanger (Point A on the Humid Air Diagram)

Table 1 Characteristics of the air at the inlet of the Exchanger (Point A on the humid air diagram).

\begin{tabular}{llll}
\hline Temperature & Relative humidity & Absolute humidity & Specific enthalpy \\
$T_{A}$ & $H r_{A}$ & $X_{A}$ & $h e_{A}$ \\
\hline $30{ }^{\circ} \mathrm{C}$ & $20 \%$ & $5.3 \mathrm{~kg} / \mathrm{kg}_{\mathrm{as}}$ & $44 \mathrm{~kJ} / \mathrm{kg}_{\mathrm{as}}$ \\
\hline
\end{tabular}

4.1.2 Air at the Outlet of the Exchanger (Point B on the Humid Air Diagram)

Table 2 Characteristics of the air at the outlet of the Exchanger (Point B on the humid air diagram).

\begin{tabular}{llll}
\hline Temperature & Relative humidity & Absolute humidity & Specific enthalpy \\
$T_{B}$ & $H r_{B}$ & $X_{B}$ & $h e_{B}$ \\
\hline $50^{\circ} \mathrm{C}$ & $5.4 \%$ & $5.3 \mathrm{~kg} / \mathrm{kg}_{\text {as }}$ & $64 \mathrm{~kJ} / \mathrm{kg}_{\text {as }}$ \\
\hline
\end{tabular}

4.1.3 Air at the Outlet of the Dryer (Point C on the Humid Air Diagram)

Table 3 Characteristics of the air at the outlet of the dryer (Point $\mathrm{C}$ on the humid air diagram).

\begin{tabular}{llll}
\hline Temperature & Relative humidity & Absolute humidity & Specific enthalpy \\
$T_{C}$ & $H r_{C}$ & $X_{C}$ & $h e_{C}$ \\
\hline $23{ }^{\circ} \mathrm{C}$ & $90 \%$ & $16 \mathrm{~kg} / \mathrm{kg}_{\text {as }}$ & $64 \mathrm{~kJ} / \mathrm{kg}_{\mathrm{as}}$ \\
\hline
\end{tabular}

\subsubsection{Heat Capacity Rate of the Air}

We determine here the heat capacity rate of the air which is calculated by the formula:

$$
\begin{aligned}
\dot{C}_{2}=\dot{C}_{\text {dry_air }}+ & \dot{C}_{\text {wat_vapor }} \\
& =\dot{m}_{\text {air }} c_{p_{\text {air }}}+X_{2} \dot{m}_{\text {air }} c_{p_{\text {wat_vapor }}}
\end{aligned}
$$

For that, we need to calculate first the mass flow rate of the dry air which is linked to the mass flow rate of water to evacuate from the products by the following equation:

$$
\dot{m}_{e}=\left(X_{C}-X_{A}\right) \dot{m}_{\text {air }}
$$

The obtained results are mentioned in the table below:

Table 4 Sizing parameters 1.

\begin{tabular}{llll}
\hline Mass flow rate of the water & $\begin{array}{l}\text { Mass flow rate of the dry air } \\
\dot{m}_{\text {air }}\end{array}$ & $\begin{array}{l}\text { Heat capacity rate of the air } \\
\dot{C}_{e}\end{array}$ & $\begin{array}{l}\text { Heat flux } \\
\Phi\end{array}$ \\
\hline $100 \mathrm{~kg} / \mathrm{h}$ & $9.4 \mathrm{~kg}_{\text {as }} / \mathrm{h}$ & $101,614 \mathrm{~J} \cdot \mathrm{K}^{-1} \cdot \mathrm{h}^{-1}$ & $2,032.28 \mathrm{~kJ} \cdot \mathrm{h}^{-1}$ \\
\hline
\end{tabular}

Table 5 Characteristics of the secondary fluid (air).

\begin{tabular}{lll}
\hline Inlet temperature & Outlet temperature & Heat capacity rate of air \\
$T_{e 2}$ & $T_{S 2}$ & $\dot{C}_{2}$ \\
\hline $30^{\circ} \mathrm{C}$ & $50^{\circ} \mathrm{C}$ & $101,614 \mathrm{~kJ} \cdot \mathrm{K}^{-1} \cdot \mathrm{h}^{-1}$ \\
\hline
\end{tabular}

4.2 Determination of the Characteristics of the Hot Fluid (Water Vapor)

Table 6 Characteristics of the primary fluid (water vapor).

\begin{tabular}{lll}
\hline Inlet temperature & Outlet temperature & Heat capacity rate of water vapor \\
$T_{e 1}$ & $T_{S 1}$ & $\dot{C}_{1}$ \\
\hline $150{ }^{\circ} \mathrm{C}$ & $131.5^{\circ} \mathrm{C}$ & $110 \mathrm{~kJ} \cdot \mathrm{K}^{-1} \cdot \mathrm{h}^{-1}$ \\
\hline
\end{tabular}

\subsection{Determination of the Heat Transfer Surface}

The overall heat transfer coefficient is calculated by the formula below $[6,7]$ :

$$
\frac{1}{K}=\frac{1}{h_{1}}+R e_{1}+\frac{e}{\lambda}+R e_{2}+\frac{1}{h_{2}}
$$

The characteristics of the hot fluid (water vapor) are mentioned in the table below:

But we assume that the thermal resistance of the exchange surface is negligible compared with the thermal resistance of the fluids. It is also assumed that the exchanger is regularly maintained so, the thermal resistance of fouling can be neglected. 
As a result, the overall heat transfer coefficient can be written as follows:

$$
\frac{1}{K}=\frac{1}{h_{1}}+\frac{1}{h_{2}}
$$

The value of the convective heat transfer coefficient of the water vapor is set to $h_{1}=280 \mathrm{~W} \cdot \mathrm{m}^{-2} \cdot{ }^{\circ} \mathrm{C}^{-1}$ and that of air is set to $h_{2}=120 \mathrm{~W} \cdot \mathrm{m}^{-2} \cdot{ }^{\circ} \mathrm{C}^{-1}$.

We can calculate the overall heat transfer coefficient, the LMTD and the heat transfer surface required to heat properly the air. The results are given in the table below:

Table 7 Sizing parameters 2.

\begin{tabular}{lll}
\hline Heat transfer oefficient & LMTD & Heat transfer surface \\
$K$ & $\overline{\Delta T}$ & $S$ \\
\hline $84 \mathrm{~W} \cdot \mathrm{m}^{-2} \cdot \mathrm{K}^{-1}$ & $101.35 \mathrm{~K}$ & $238.71 \mathrm{~m}^{2}$ \\
\hline
\end{tabular}

\section{Conclusion}

This paper presents an energy analysis of a counter-flow plate heat exchanger operating in stationary mode. The analyzed parameters are the NTU, the effectiveness, the temperatures of both hot and cold fluid and the heat flux. The evolution of these parameters is studied according to the variation of the heat transfer surface of the exchanger. It appears from this work that the heat transfer between the hot and the cold fluid is better for large heat transfer surfaces.

This analysis is completed by the determination of the heat transfer surface required by a plate exchanger to properly heat air used for the drying of products. That exchanger uses water vapor heated by geothermal energy as a primary fluid and ambient air as a secondary fluid.

\section{References}

[1] Bontemps, A., Garrigue, A., Goubier, C., Huetz, J.,
Marvillet, C., Mercier, P., and Vidil, R. Echangeurs de chaleur, Description des échangeurs.

[2] Bontemps, A., Garrigue, A., Goubier, C., Huetz, J., Marvillet, C., Mercier, P., and Vidil, R. Echangeurs de chaleur, Définitions et architecture générale.

[3] Jeannot, Y. 2002. Transferts Thermiques.

[4] Bontemps, A., Garrigue, A., Goubier, C., Huetz, J., Marvillet, C., Mercier, P., and Vidil, R. 1998. Echangeurs de chaleur, Dimensionnement thermique.

[5] Dieng, B., and Jaw, G. 2012. "Characterization of a Cold Battery with Iced Water and Double Heat Exchanger in a Humid Mode." Journal of Information Engineering \& Applications 2 (9): 12-25.

[6] Dieng, B., Jaw, G., Kane, A., Diagne, I., and Sissoko, G. 2015. "Determination of the Operating Point and the Enthalpy Per Unit Surface of a Cold Battery With Icy Water and a Double Heat Exchanger." International Journal of Engineering Research 4 (11): 609-12.

[7] Dieng, B., Jaw, G., Kane, A., Diagne, I., Dieng, M., and Sissoko, G. 2015. "Determination of the Global Heat Transfer Coefficient of a Double Heat Exchanger Battery in a Dry Mode." International Journal of Scientific Engineering and Technology 4 (12): 545-8. 